\title{
Chronic iatrogenic lateral root perforation with open apex
}

\author{
Pushpendra Kumar Verma', Ruchi Srivastava², Srivastava MC $^{3}$
}

Quick Response Code

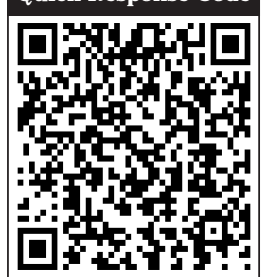

doi: $10.5866 / 2015.7 .10217$

${ }^{1}$ Associate Professor,

Department of Conservative Dentistry and

Endodontics, Saraswati Dental College and Hospital, Lucknow, 227105, Uttar Pradesh, India.

${ }^{2}$ Associate Professor,

Department of Periodontics,

Saraswati Dental College and Hospital,

Lucknow, 227105, Uttar Pradesh, India.

${ }^{3}$ Assistant Professor,

Department of Medicine,

Prasad Institute of Medical Sciences,

Lucknow, Uttar Pradesh, India.

\section{Article Info:}

Received: J uly 10, 2015

Review Completed: August 11, 2015

Accepted: September 12, 2015

Available Online: J uly, 2015 (www.nacd.in)

C NAD, 2015 - All rights reserved

\section{Email for correspondence:}

pushpendrakgmc@gmail.com

\section{Introduction}

According to the American Association of Endodontists (AAE) Glossary of Endodontic Terms, root perforations are mechanical or pathological communications between the root canal system and the external tooth surface. ${ }^{1}$ Perforation may occur pathologically by resorptive processes, caries, or it may occur iatrogenically as a complication during preparation of access cavities, coronal shaping or

\begin{abstract}
:
Root perforation is a mechanical or pathological communication formed between the supporting periodontal apparatus of the tooth and root canal system. The crowns of many teeth are often perforated during access cavity preparation dueto misalignment of bur along the long axis of the root or when the anatomical variations are not anticipated. This case report reveals the healing process of chronic iatrogenic lateral root perforation repaired with mineral trioxide aggregate (MTA). MTA is a bioactive silicate cement which is nonirritating to the periapical tissues and also provides an effective seal against dentin and cementum and promotes biologic repair and regeneration of the periodontal ligament. MTA has an advantage to seal the communication from external surface of the tooth for perforation repair. MTA is also used as an obturation material that may provide long-term benefits and enhance the prognosis and retention of the natural dentition. Successful perforation repair depends on the ability to seal the perforation and to re-establish a healthy periodontal ligament.
\end{abstract}

Key words: Chronic root perforation, mineral trioxide aggregate, open apex, perforation repair.

during post-space preparation either with hand or rotary instruments. ${ }^{2}$ Root perforations are significant complications of endodontic treatment and, if not detected and properly treated, the breakdown of the periodontium may ultimately lead to tooth loss. Injury to the periodontium results in development of inflammation, destruction of periodontal fibers, bone resorption, formation of granulomatous tissue, proliferation of epithelium 
and ultimately in the development of a periodontal pocket. ${ }^{3,4}$ Time lapse between the creation of a perforation and its repair is critical for the prognosis of a tooth. ${ }^{5}$ The etiology of perforation plays a major role in determining the management protocol. The diagnosis is established based on clinical and radiographic assessment. The radiographical detection of root perforations, especially on the buccal or lingual root surfaces, is often impractical since the image of the perforation is superimposed on intact root structure. Radiographs from multiple angles, including bitewing radiographs and threedimensional information acquired from computed tomography (CT) or cone beam CT scans can provide additional and more conclusive information. ${ }^{6}$ While planning treatment for perforation repair, the location of the perforation is the most important factor in the decision-making process. ${ }^{7}$ Non-surgical treatment is indicated, whenever possible, in the management of perforations. Surgical intervention is taken into consideration when the case does not respond to non-surgical treatment, or in which the concomitant management of the periodontium is indicated. There is no absolute distinction between those cases that are best treated non-surgically and those treated surgically, and at times, combinations of both non-surgical and surgical approaches must be adopted. This article presents a non-surgical management of a case with chronic lateral root perforation with an open apex.

\section{Case Report}

A female patient $20 \mathrm{yrs}$ of age came with a chief complain of pain and discoloration in upper anterior tooth. Patient had a history of trauma 12 years back in maxillary anterior region. Patient also revealed a past dental history of attempt of root canal treatment by a private dentist 10 years back and during access cavity preparation, a perforation occurred with bur. After that the patient remained asymptomatic. On present clinical examination there was a lateral perforation of tooth 11 (Figure 1). On radiographic examination there was a lateral root surface perforation at crestal bone level and an open apex of tooth 11 (Figure 2). Treatment was initiated by preparation of correct access opening and working length was determined at first visit
(Figure 3). Root canal was debrided and irrigated with $3 \%$ sodium hypochlorite. Subsequently apexification was done with MTA with help of plugger at second visit (Figure 4). Then a collagen barrier/foam was placed into the perforation and perforation was sealed with MTA simultaneously filling the complete canal with MTA (Figure 5). The access cavity was sealed with GIC and a crown was placed. Patient was recalled after 2 year follow-up (Figure 6 and 7). The patient was asymptomatic and clinical examination revealed complete healing of periodontal tissues and absence of periodontal pocket.

\section{Discussion}

The aim of perforation repair is to maintain a healthy periodontium without persistent inflammation or loss of periodontal attachment. The incidence of perforations is quoted in the literature as being between $3-10 \% .{ }^{8}$ According to K vinnsland et al. $53 \%$ of iatrogenic perforations occur during insertion of posts (prosthodontic treatment); the remaining $47 \%$ are induced during routine endodontic treatment. ${ }^{9}$ Adequate knowl edge is required for location and dimensions of the pulp chamber as well as the anatomical variations of a specific tooth treated in order to prevent complications. Fuss \& Trope presented a classification that emphasized the relationship of a perforation site to the 'critical crestal zone'. ${ }^{10}$ This classification divides the root into coronal, crestal and apical portions: coronal being defined as 'coronal to the crestal bone and epithelial attachment'; crestal being defined as 'at the level of the epithelial attachment and crestal bone' and apical being defined as 'apical to the crestal bone and epithelial attachment'. Various materials have been used in managing perforations, including zinc oxideeugenol, amalgam, calcium hydroxide, composite resin, glass ionomer and resinmodified glass ionomer. ${ }^{11,}{ }^{12}$ The ideal material for treating radicular perforations should be nontoxic, nonabsorbable, radiopaque, and bacteriostatic or bactericidal; it should also provide a seal against microleakage from the perforation. Mineral trioxide aggregate (MTA) has all of these characteristics and has been applied with good outcomes in root-end 


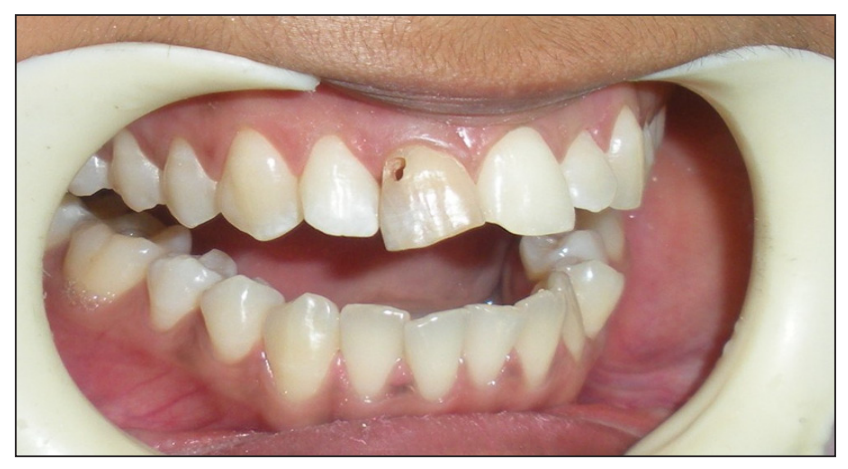

Figure 1: Pre-operative view showing lateral perforation of tooth 11.

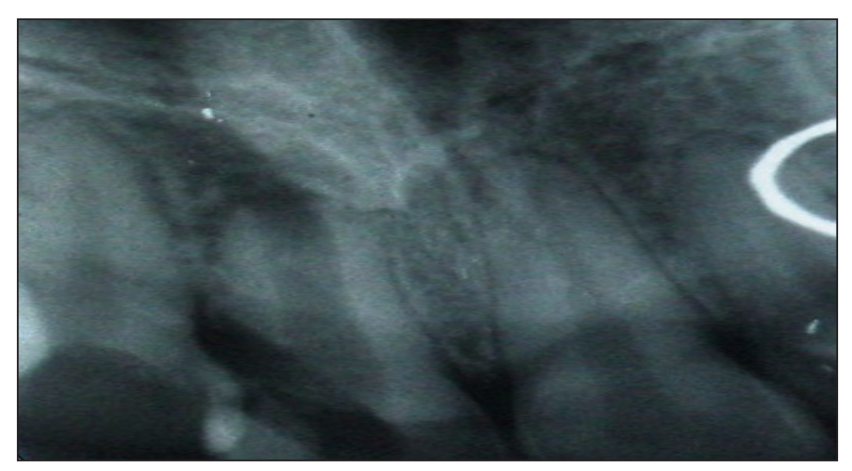

Figure 2: IOPA X-ray showing lateral root surface perforation at crestal bone level and an open apex of tooth 11 .

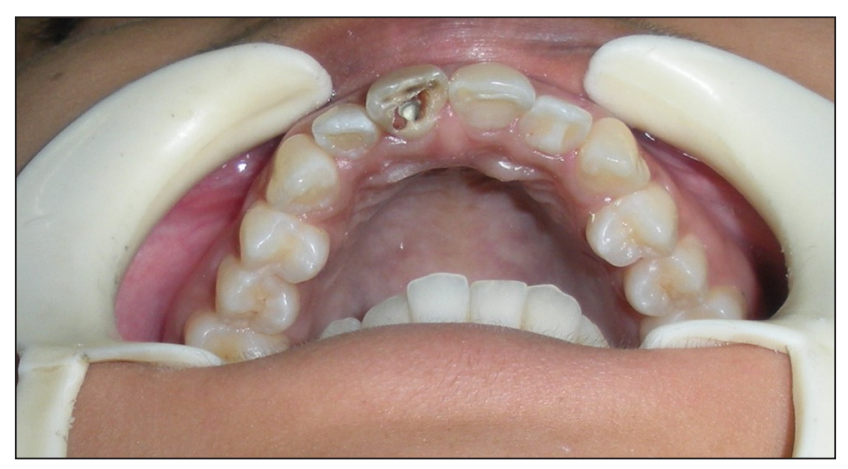

Figure 3: Restoration with MTA at first visit.

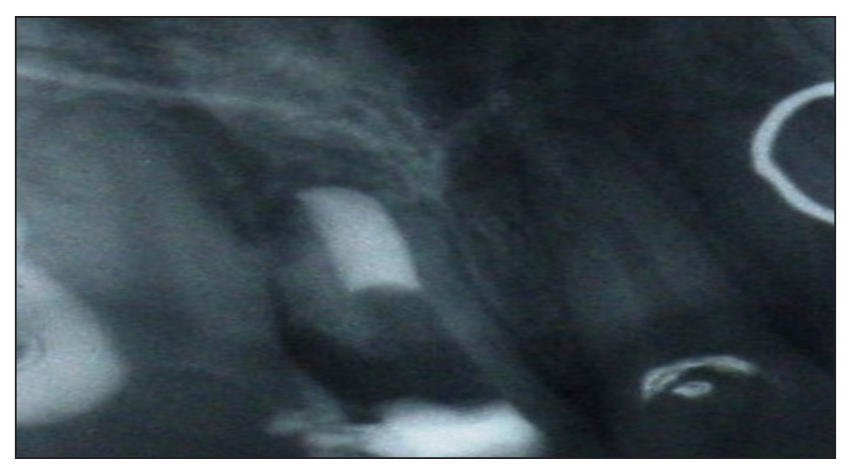

Figure 4: IOPA X-ray after apexification at second visit

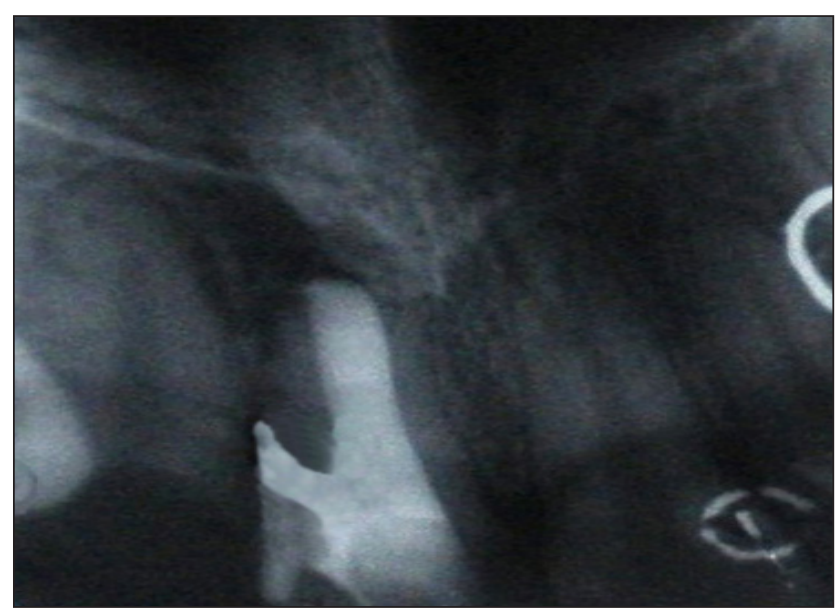

Figure 5: IOPA showing perforation repair and obturation with MTA.

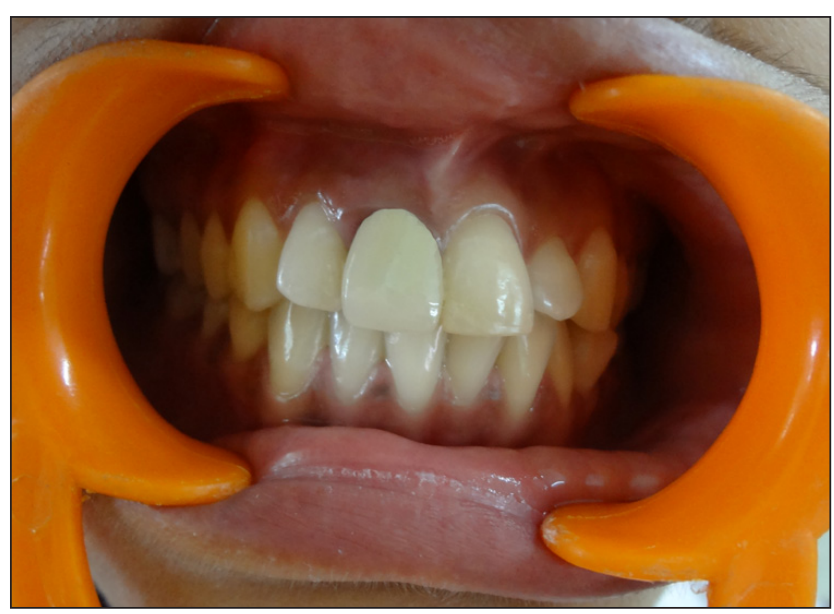

Figure 6: Post-operative view after the access cavity was sealed with GIC and a crown was placed.

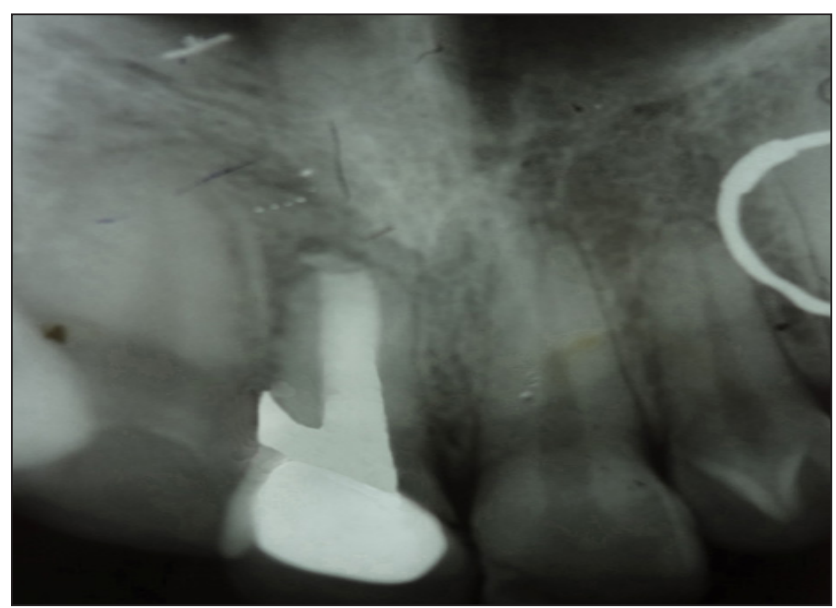

Figure 7: IOPA after 2 years follow-up shows complete healing of periodontal tissues and absence of periodontal pocket. 
surgery, direct pulpal coverage, apexification, radicular resorption, and repair of lateral radicular and furcal perforation. ${ }^{13}$ The MTA as an original material (Pro-Root MTA; Dentsply Tulsa Dental, Tulsa, OK) was introduced to seal pathways of communication from the external surface of the tooth in perforation repair and as a root-end filling material in endodontic surgery. ${ }^{14}$ In conjunction with being sterile, radiopaque, and nonshrinking, the material is nonirritating to periapical tissues. It has antimicrobial properties and high pH (12.5) of MTA, which promote growth of the cementum and formation of bone, which in turn allow regeneration of the periodontal ligament around the site of injury. ${ }^{15}$ The two main challenges for a clinician, when attempting to repair a perforation are hemostasis and the controlled placement of a restorative material. Most materials used for repair are sensitive to moisture, frequently compromising the seal of the repair material and resulting in unfavorable outcomes; controlling hemostasis is of major importance in achieving a tight seal. As these cases are frequently present with hyperplastic and hypervascular granulation tissue which protrudes into the defect; the removal of these tissues is necessary and sometimes makes hemostasis challenging. Hemostasis is achieved using collagen, calcium sulphate, or calcium hydroxide. MTA sets in the presence of moisture and blood does not affect its sealing ability. ${ }^{16}$ Sluyk et al. demonstrated that the presence of moisture in perforations during the placement of MTA increased its adaptation to perforation walls. ${ }^{17}$ Also the repair of a perforated defect is complicated when there is extrusion of the repair material into surrounding structures. This usually occurs during condensation of filling material into the perforation site and can cause traumatic injury to the surrounding periodontal ligament. The next important factor is the degree of bone destruction and the resulting defect surrounding the perforation. If there is no intraosseus defect, no barrier is needed but in cases with larger osseous defects, the careful use of a barrier can facilitate proper placement and adaptation of the filling material as well as prevent overcontouring. The extrusion of repair materials often delays the repair process. MTA is known to be biocompatible and form new cementum formation with regeneration of the entire periodontium, despite its extrusion into the periradicular tissues, similar to when used in root-end fillings. ${ }^{18}$

As the case mentioned in this report, the existing and probably infected perforations, at cervical and occasionally mid-root perforations that are frequently associated with epithelial down growth and subsequent periodontal defects, had a compromised prognosis. Success in the treatment of infected perforations seems to be attributed to removal of contaminants before repairing under aseptic conditions using burs or ultrasonic under magnification. Disinfecting solution such as sodium hypochlorite can improve antimicrobial interaction and is helpful, but it should be used carefully, with the awareness of the increased risk of severe complications.

Mineral trioxide aggregate (MTA) has a profound advantage when used as canal obturation material because of its superior physiochemical and bioactive properties. Because perforation repair, root-end induction and root-end filling are essentially forms of partial canal obturation, the orthograde filling of the apical region or the entire root canal system with MTA is the next logical progression in the evolutionary application of this material. The cement is an osteoinductive and cementogenic agent that stimulates immune cells to release lymphokines required for the repair and regeneration of cementum and stimulates bone coupling factors necessary for the bioremineralization and healing of osseous periapical defects. ${ }^{19} \mathrm{MTA}$ also induces the formation of apical cal cific barriers and resolution of periapical disease of unformed apices in teeth with necrotic pulps. MTA obturations in teeth with immature apices can induce apexogenesis by stimulating the mesenchymal stem cells from the apical papilla to promote complete root maturation in the presence of periapical pathosis or abscesses. ${ }^{20}$ The sealing ability of MTA in perforation repair is remarkable and so it can be considered as routine method for treating procedural errors in endodontic therapy. 


\section{Conclusion}

In conclusion, root perforations are severe complications which affect the prognosis of endodontic procedures. Treatment can be challenging and sometimes require certain creativity. The prognosis of teeth with root perforations depends on the severity of the initial damage to the periodontal tissues, the size of the perforation, the location of the perforation in relation to the gingival sulcus, the timelapse between injury and repair, the adequacy of the perforation seal, the sterility of the perforation and the biocompatibility of the material used to repair the perforation. MTA seems to be an excellent and promising material for the repair of perforations.

\section{References:}

1. Glossary of Endodontic Terms. Chicago, IL: American Association of Endodontists, 2003.

2. Roda RS. Root perforation repair: surgical and nonsurgical management. Pract Proced Aesthet Dent 2001; 13:467-472.

3. Seltzer S, Sinai I, August D. Periodontal effects of root perforations before and during endodontic procedures. J Dent Res 1970; 49:332-339.

4. Tsesis I, Fuss Z. Diagnosis and treatment of accidental root perforations. Endodontic Topics 2006; 13:95-107.

5. Lemon RR. Nonsurgical repair of perforation defects. Internal matrix concept. Dent Clin North Am 1992; 36:439457.

6. Tsurumachi T, Honda K. A new cone beam computerized tomography system for use in endodontic surgery. Int Endod J 2007; 40:224-232.

7. Menezes R, da Silva Neto UX, Carneiro E, Letra A, Bramante CM, Bernadinelli N. MTA repair of a supracrestal perforation: a case report. J Endod 2005; 31:212-214.

8. Eleftheriadis GI, Lambrianidis TP. Technical quality of root canal treatment and detection of iatrogenic errors in an undergraduate dental clinic. Int Endod J 2005; 38:725-734.
9. Kvinnsland I, Oswald RJ, Halse A, Gronningsaeter AG. A clinical and roentgenological study of 55 cases of root perforation. Int Endod J 1989; 22:75-84.

10. Fuss Z, Trope M. Root perforations: classification and treatment choices based on prognostic factors. Endod Dent Traumatol 1996; 12:255-264.

11. De-Deus G, Reis C, Brandão C, Fidel S, Fidel RA. Theability of Portland cement, MTA, and MTA Bio to prevent throughand-through fluid movement in repaired furcal perforations. J Endod 2007; 33(11):1374-1377.

12. Verma PK, Srivastava R. Calcium hydroxide - A boon in complete healing of horizontal apical one third root fracture. Dental Hypotheses 2012; 3:121-125.

13. Thomas C, Shin SJ. Repair of perforations with MTA: clinical applications and mechanisms of action. Endodontic Topics 2009; 15:32-55.

14. Torabinejad M, Watson TF, Pitt Ford TR. Sealing ability of a mineral trioxide aggregate when used as root end filling material. J Endod 1993; 19:591-595.

15. Roberts HW, Toth J M, Berzins DW, Charlton DG. Mineral trioxide aggregate material use in endodontic treatment: a review of the literature. Dent Mater 2008; 24(2): 149-164.

16. Torabinejad M, Higa RK, McKendry DJ , Pitt Ford TR. Dye leakage of four root end filling materials: effects of blood contamination. J Endod 1994; 20:159-163.

17. Sluyk SR, Moon PC, Hartwell GR. Evaluation of setting properties and retention characteristics of mineral trioxide aggregate when used as a furcation perforation repair material. J Endod 1998; 24:768-771.

18. Bernabe PF, Gomes-FilhoJ E, Rocha WC, Nery MJ , OtoboniFilho J A, Dezan-J unior E. Histological evaluation of MTA as a root-end filling material. Int Endod J 2007; 40:758765.

19. Economides N, Pantelidou O, Kokkas A, Tziafas D. Shortterm periradicular tissue response to mineral trioxide aggregate (MTA) as a root-end filling material. Int Endod J 2003; 36: 44-48.

20. Huang GT, SonoyamaW, Liu Y, Wang S, Shi S. The hidden treasure in apical papilla: the role in pulp/dentin regeneration and bioroot engineering. J Endod 2008; 34: 645-651.

\section{Gain quick access to our journal online View our journal at www.nacd.in}

